\title{
Integrity and characteristics of secondary oesophageal peristalsis in patients with gastro-oesophageal reflux disease
}

\author{
M N Schoeman, R H Holloway
}

\begin{abstract}
Secondary peristalsis contributes to oesophageal acid clearance. The aim of the study was to evaluate the integrity and characteristics of secondary peristalsis in patients with gastro-oesophageal reflux disease. Studies were performed in 22 patients with reflux disease and 20 age matched controls. Oesophageal motility was recorded at $3 \mathrm{~cm}$ intervals along the oesophageal body. Primary peristalsis was tested with $5 \mathrm{ml}$ water swallows. Secondary peristalsis was stimulated with $10 \mathrm{ml}$ boluses of air and water injected in the mid-oesophagus and by 5 second distensions with a $3 \mathrm{~cm}$ balloon at the same level. It was found that primary peristalsis was normal in 19 of 20 control subjects and in 14 of 22 patients with reflux disease. In patients with reflux disease, intact secondary peristalsis was triggered infrequently by air and water distension (median success rate of $0 \%$ for both stimuli) and occurred significantly less frequently than in control subjects $(50 \%$ and $30 \%$ respectively). The frequency of balloon induced secondary peristalsis, however, was similar in the two groups ( $0 \%$ controls, $20 \%$ reflux disease). The major pattern of failure of secondary peristalsis was the complete absence of any oesophageal secondary peristaltic response. The amplitudes of the intact secondary peristaltic responses were not significantly different for the two groups. Peristaltic velocity for air and balloon induced secondary peristalsis was also similar in control subjects and patients with reflux disease whereas water induced secondary peristalsis was slower in the reflux patients. In conclusion, patients with reflux disease exhibit a pronounced defect in the triggering of secondary peristalsis.

(Gut 1995; 36: 499-504)
\end{abstract}

Gastroenterology Unit, Royal Adelaide Hospital, North Terrace, Adelaide, South Australia $M$ N Schoeman R H Holloway

Correspondence to: Dr R H Holloway, Department of Gastroenterology, Royal Adelaide Hospital, North Terrace, Adelaide, South Australia, 5000.

Accepted for publication 8 August 1994
Keywords: primary peristalsis, secondary peristalsis, oesophageal motility, gastro-oesophageal reflux.

Secondary peristalsis is triggered by oesophageal distension ${ }^{1-7}$ and contributes to oesophageal volume clearance after reflux. ${ }^{8}$ It is the initial oesophageal motor event after most reflux episodes in normal subjects. ${ }^{9}$ In patients with reflux disease, however, it has been reported to occur less often after reflux ${ }^{10}$ suggesting that triggering of secondary peristalsis may be abnormal in such patients. A systematic study of secondary peristalsis in patients with reflux disease, however, has not been reported. Studies of the oesophageal motor responses to prolonged balloon distension have shown a higher threshold to distension and fewer contractions during the period of distension in patients with reflux disease, these findings being correlated with greater severity of oesophagitis and delayed oesophageal acid clearance. ${ }^{11}$ Other studies, however, have found the threshold to trigger a secondary peristaltic response to comparatively slow instillation of water or acid in patients with reflux disease to be similar to that in normal subjects. ${ }^{1213}$ We have recently performed a systematic evaluation of secondary peristalsis in young normal subjects using three different stimuli, air and water boluses, and oesophageal balloon distension. ${ }^{5}$ The aims of this study were to investigate in detail, the integrity and characteristics of secondary peristalsis in patients with gastro-oesophageal reflux disease and to examine the effect of different stimuli on the motor response.

\section{Methods}

\section{SUBJECTS}

Twenty two patients with gastro-oesophageal reflux disease (females 8: males 14), ranging in age from 23-85 years (median 57), were recruited for the study. All patients complained of reflux symptoms, such as heartburn and acid regurgitation and had either erosive oesophagitis at endoscopy $(n=17)$ or excessive oesophageal acid exposure ( $\mathrm{pH}<4$ for $>5 \%$ of total time) during 24 hour oesophageal ambulatory $\mathrm{pH}$ monitoring $(\mathrm{n}=5)$. Those with endoscopic evidence of oesophagitis were studied before treatment. Nine of 22 patients complained of intermittent dysphagia but none of these had any structural obstructive lesion at endoscopy. Patients taking drugs that may have affected oesophageal motility stopped these at least 48 hours before the study.

Twenty age matched healthy subjects (females 8: males 12) ranging in age from 23-76 years (median 50 ) served as controls. Subjects were free of gastrointestinal symptoms, had no history of upper gastrointestinal surgery, were not taking antacids regularly or any drugs known to change oesophageal motor function.

All patients and volunteers gave written informed consent and the study was approved 


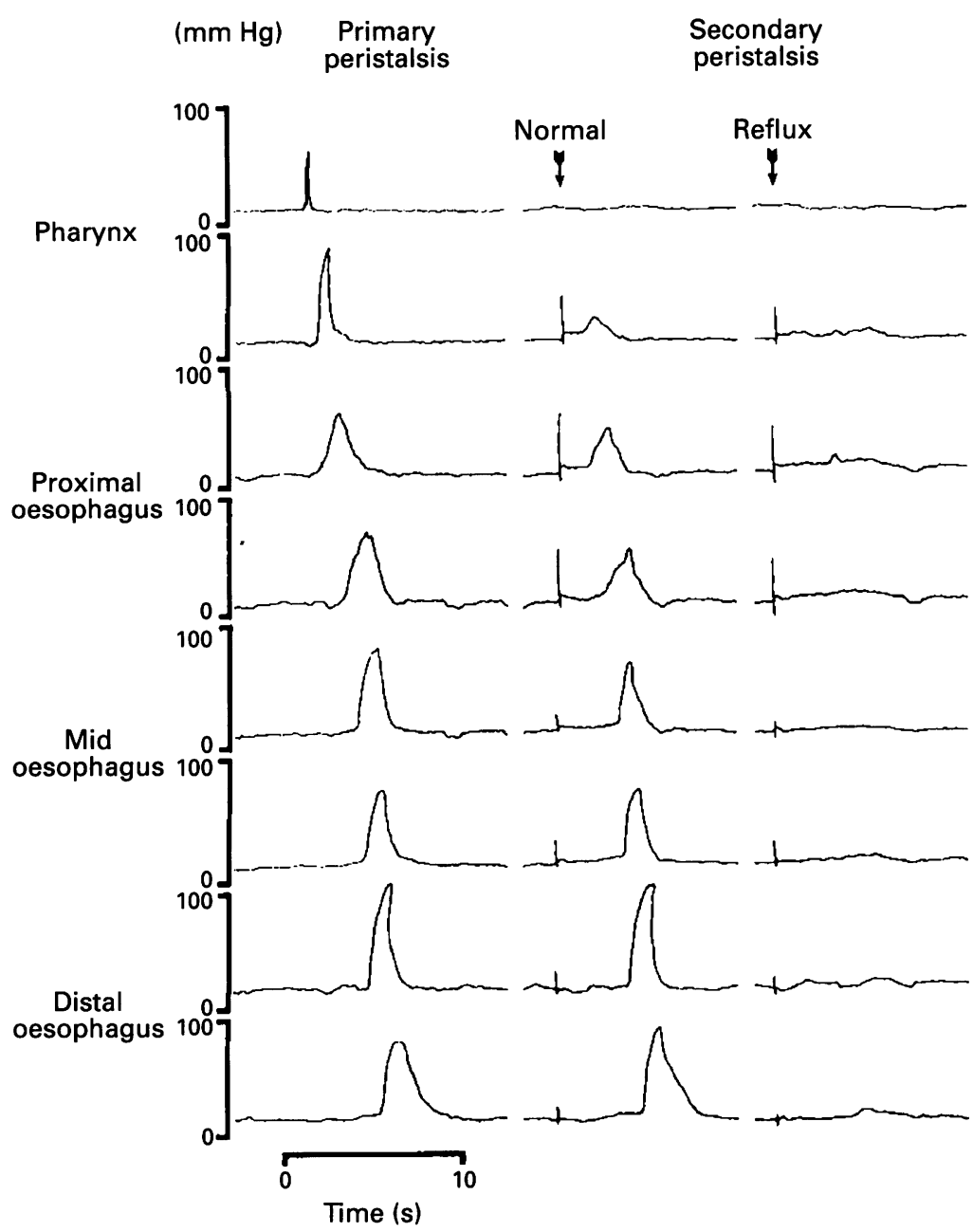

Figure 1: Pressure tracing showing primary peristalsis triggered by a water swallow and typical secondary peristaltic responses triggered by a $10 \mathrm{ml}$ air bolus injection in the normal subjects and patients with reflux disease. The arrow shows the time of bolus injection. In the normal subjects, a secondary peristaltic wave would traverse the oesophageal body while in the reflux patients there was usually no response.

by the human ethics committee of the Royal Adelaide Hospital.

\section{MANOMETRY}

Oesophageal motility was recorded with a 13 lumen manometric assembly made from a $4 \cdot 5$ $\mathrm{mm}$ diameter silicon rubber extrusion that incorporated a $6 \mathrm{~cm}$ sleeve sensor. ${ }^{14}$ Side holes, spaced $3 \mathrm{~cm}$ apart, recorded pressures from seven sites along the oesophageal body starting at $2 \mathrm{~cm}$ above the proximal margin of the lower oesophageal sphincter. A side hole in the gastric fundus recorded gastric pressure and a side hole in the pharynx monitored swallowing. A $3 \mathrm{~cm}$ long silicon rubber balloon, which fitted tightly around the catheter assembly when deflated provided focal distension $12.5 \mathrm{~cm}$ above the lower oesophageal sphincter. An infusion port was located immediately above the balloon for the rapid injection of boluses of air or water. The catheter was fixed and maintained in position so that the mid-portion of the sleeve sensor was located within the lower oesophageal sphincter. The oesophageal and gastric side holes and the sleeve sensor were perfused with degassed distilled water at $0.6 \mathrm{ml} / \mathrm{min}$ by a low compliance pneumohydraulic capillary infusion system. ${ }^{15}$ The pharyngeal side hole was perfused at $0.3 \mathrm{ml} / \mathrm{min}$. Pressures were sensed by external pressure transducers (Deseret Medica, Park Davis, Sandy Utah, USA, Model 38-8000-1) with output to a 12 channel polygraph recorder (Grass Instrument, Quincy, MA, USA, Model 7D). Recordings were made at a paper speed of $5 \mathrm{~mm} / \mathrm{s}$.

STUDY PROTOCOL

After an overnight fast, the catheter was passed through the nose. The subjects were studied supine. After a 10 minute adaptation period, both primary and secondary peristalsis were tested in each subject.

Primary peristalsis was tested with ten, $5 \mathrm{ml}$ water swallows. Each swallow was separated by an interval of 30 seconds. Secondary peristalsis was triggered by oesophageal distension with $10 \mathrm{ml}$ boluses of air and water and by inflating the intra-oesophageal balloon. Each stimulus was tested five times. Balloon distension was only performed in 16 of 22 patients because of technical problems such as balloon rupture (two subjects) or intolerance of balloon distension caused by chest discomfort (four subjects). The air and water boluses were rapidly injected through the infusion port by hand. The $10 \mathrm{ml}$ air bolus was injected within 0.5 seconds, while the $10 \mathrm{ml}$ water bolus was delivered within 1.5 seconds. The balloon was inflated with $17 \mathrm{ml}$ of air to a diameter of $3 \mathrm{~cm}$ within 0.5 seconds and sustained for five seconds before being quickly deflated over 0.5 seconds. The distending stimuli were given from 15 to 20 seconds after any preceding primary peristaltic wave and there were no systematic differences in this interval among stimuli or between subject groups. An interval of 20 seconds was permitted after each stimulus for any response to occur. This interval was selected as it is comparable with the latency of the secondary peristaltic response after physiological reflux events. ${ }^{10}$ During this time the subjects were instructed not to swallow. At the end of the 20 second period the subject was asked to perform a dry swallow that served to reduce the desire of the subject to swallow during the distension stimulus as well as to clear any residual air or water.

\section{DATA ANALYSIS}

The contraction amplitude at each recording site and the latency of the wave onset between adjacent recording sites were determined for both primary and secondary peristalsis. Amplitude was measured from basal end expiratory intraoesophageal pressure to the peak of the pressure wave. The onset of the major upstroke of the pressure wave was used as the reference point for determination of the wave latency.

Primary peristalsis was classified as complete if a propagated pressure wave of $\geqslant 12 \mathrm{~mm} \mathrm{Hg}$ in the proximal two oesophageal body channels and $\geqslant 25 \mathrm{~mm} \mathrm{Hg}$ in the distal five oesophageal channels, traversed all the recording sites. ${ }^{16} 17$ The minimum latency of wave onset between 
adjacent recording sites that defined peristaltic progression was set at 0.5 seconds, corresponding to a peristaltic velocity of $6 \mathrm{~cm} / \mathrm{s}$. Criteria for failed peristalsis were either failure of a pressure wave, $\geqslant 12 \mathrm{~mm} \mathrm{Hg}$ in the proximal two oesophageal channels and $\geqslant 25 \mathrm{~mm} \mathrm{Hg}$ in the distal five channels, to traverse each of the oesophageal recording sites or synchronous pressure waves occurring at two or more recording sites. In addition, no response to distension was judged to have occurred if a pressure wave $\geqslant 10 \mathrm{~mm} \mathrm{Hg}$ was seen in less than two recording sites. For complete peristaltic responses, mean amplitude and velocity were calculated for the five distal recording sites corresponding to the distal $12 \mathrm{~cm}$ of the smooth muscle segment of the oesophageal body. Normal primary peristalsis was defined as the occurrence of eight or more complete peristaltic responses to the 10 water swallows. ${ }^{18}$

Secondary oesophageal motor responses to air and water boluses were typically characterised by a propagated pressure wave that traversed the entire oesophagus (Fig 1), and were analysed according to the criteria given above for primary peristalsis. The response to balloon distension, however, was different from the response triggered by the air and water injections as there were separate responses above and below the balloon. During balloon inflation, a sustained pressure wave was seen above the balloon with inhibition of motor activity below. After balloon deflation, the pressure wave above the balloon subsided and a motor response was seen below the balloon. ${ }^{5}$ Each component of the balloon response was analysed individually using the same criteria as for primary peristalsis.

\section{STATISTICAL ANALYSIS}

The frequencies of successful primary and secondary peristalsis were determined in each subject as a percentage of the number of tests for each stimulus. Differences in response rates among stimuli were analysed using log linear

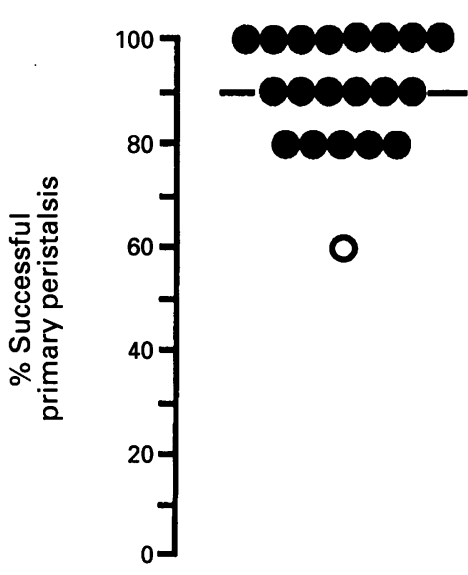

Normal

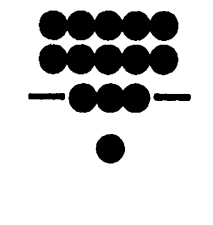

$\mathbf{0}$
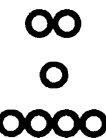

\section{Reflux}

Figure 2: The percentage of complete primary peristaltic responses for each subject. Subjects defined as having normal primary peristalsis are represented by the filled circles and those with abnormal primary peristalsis with the open circles. The horizontal bars show the median values. There was no statistical difference in the response rates between tbe groups.
Peristaltic amplitude and velocity

\begin{tabular}{lll}
\hline & Normal subjects & Reflux patients \\
\hline Amplitude (mm $\mathrm{Hg})$ & & \\
Primary peristalsis & $80 \cdot 6(2 \cdot 1)$ & $82 \cdot 0(1 \cdot 9)$ \\
$\begin{array}{l}\text { Secondary peristalsis } \\
\quad \text { Air injection }\end{array}$ & $77 \cdot 1(3 \cdot 5)$ & $75 \cdot 9(5 \cdot 1)$ \\
$\quad$ Water injection & $73 \cdot 2(3 \cdot 2)$ & $76 \cdot 6(5 \cdot 4)$ \\
$\quad$ Balloon distension & $68 \cdot 1(3 \cdot 2)$ & $77 \cdot 9(8 \cdot 5)$ \\
Velocity (cm/s) & & \\
Primary peristalsis & $2 \cdot 8(0 \cdot 04)$ & $2 \cdot 6(0 \cdot 05) \dagger$ \\
Secondary peristalsis & $2 \cdot 9(0 \cdot 08)$ & $2 \cdot 7(0 \cdot 22)$ \\
$\quad$ Air injection & $2 \cdot 6(0 \cdot 11)$ & $2 \cdot 1(0 \cdot 16) \ddagger$ \\
$\quad$ Water injection & $2 \cdot 7(0 \cdot 19)$ & $2 \cdot 9(0 \cdot 26)$ \\
\hline
\end{tabular}

Data expressed as mean (SEM). *Secondary peristaltic responses induced by balloon distension occurred below the balloon after deflation. $t p=0.001$ compared with normal balloon after deflation. $\nmid p=0.001$ compared with no
subjects. $\neq p=0.04$ compared with normal subjects.

modelling techniques. ${ }^{19}$ Data for peristaltic amplitude and velocity, and the pattern of oesophageal motor responses to distension were pooled and subjected to analysis of variance. ${ }^{20}$ The proportions of the various motor responses to distension for all tests in all subjects were also pooled for each stimulus and subjected to $\chi^{2}$ analysis. Group data for response rates are expressed as median values and those for peristaltic amplitude and velocity as mean (SEM).

\section{Results}

PRIMARY PERISTALSIS

Nineteen of the normal subjects (95\%) and 14 of 22 reflux patients (64\%) exhibited complete peristaltic responses with at least eight of 10 water swallows and were defined as having normal primary peristalsis (Fig 2). Overall, the median frequency of successful primary peristalsis in the reflux patients $(90 \%)$ was the same as that in the normal subjects $(90 \%)$ $(p=0.46)$. Eight of 22 reflux patients $(36 \%)$, however, had an abnormal frequency of successful primary peristalsis with a median response rate in these subjects of only $5 \%$. All of the abnormal peristaltic responses were of the failed pattern. The Table summarises contraction amplitudes and propagation velocities of successful peristalsis. Primary peristaltic amplitude was similar in the two groups but peristaltic velocity was significantly slower in the reflux patients $(p=0.001)$.

The median response rate in patients with endoscopic oesophagitis $(85 \%)$ was not significantly different from that in patients without oesophagitis $(95 \%)$. Of the nine patients with reflux disease who complained of dysphagia, five $(56 \%)$ had normal primary peristalsis. Similarly, 9 of 13 patients $(69 \%)$ without dysphagia had normal primary peristalsis.

\section{SECONDARY PERISTALSIS}

\section{Air and water boluses}

The frequencies of successful secondary peristalsis in response to oesophageal distension with air and water injections were significantly higher in the normal subjects than in the reflux patients (Fig 3) but were not significantly 
Air

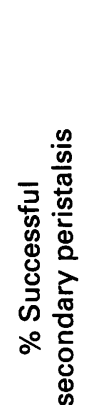

Water

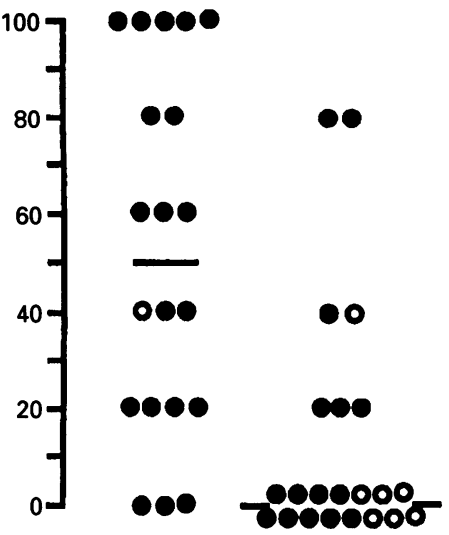

Normal
Reflux

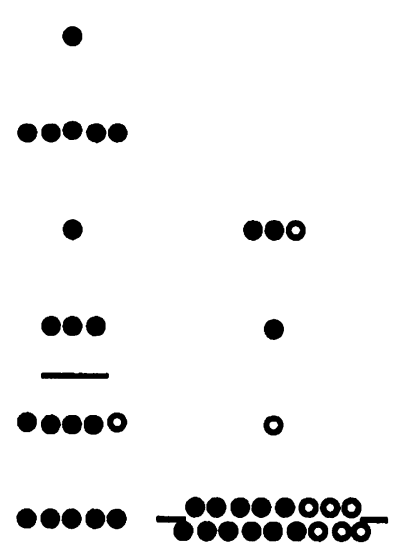

Normal

\section{Reflux}

Figure 3: Percentage of secondary peristalsis with air and water bolus injections. Each point represents the proportion of normal secondary peristaltic responses (out of five tests) for each subject. Subjects with normal primary peristalsis are represented by the filled circles and those with abnormal primary peristalsis with the open circles. The horizontal bars show median values. The frequency of the responses for both stimuli were significantly less in the reflux patients compared with the normal volunteers $(p \leqslant 0.003)$.

different in patients with or without oesophagitis. These differences were maintained when patients (and the one normal subject) with abnormal primary peristalsis were excluded from the analysis. The median response rate with air injection was $50 \%$ in the normal subjects and $0 \%$ in the patients $(p=0.0005)$. Similarly, the median success rate with water

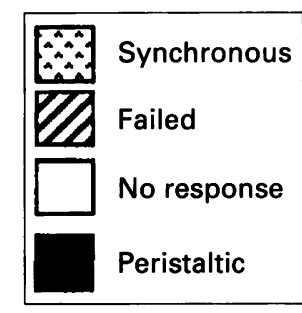

Air

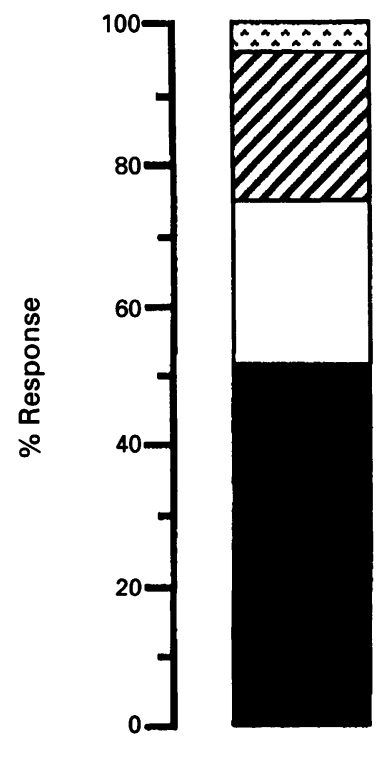

Normal

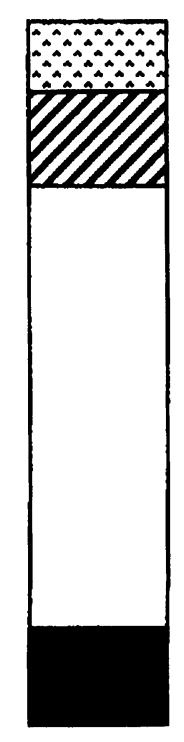

Reflux
Water

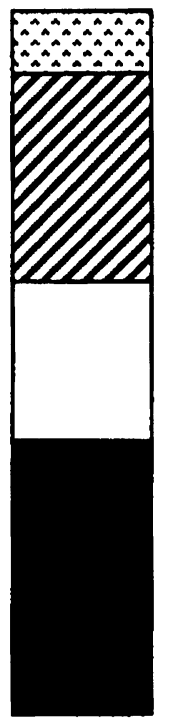

Normal

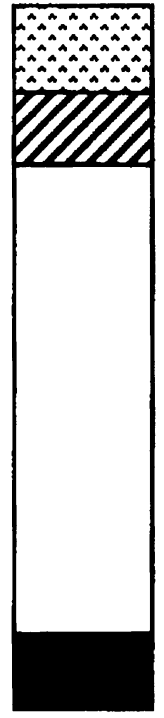

Reflux

Figure 4: Patterns of manometric response to $10 \mathrm{ml}$ boluses of air and water. The proportions of the various patterns of manometric response are derived from pooled data of the individual responses. The most common pattern of failure of secondary peristalsis in the reflux patients was no response.

injections was $30 \%$ in the normal subjects and $0 \%$ in the reflux patients $(p=0.003)$. Within each group, however, the frequency of secondary peristalsis in response to air did not differ from that in response to water. There was no correlation between the frequency of primary and secondary peristalsis with either stimulus and most patients with abnormal secondary peristalsis had normal primary peristalsis. In patients with normal primary peristalsis, the prevalence of defective secondary peristalsis, triggered by the air and water boluses, was similar in those with dysphagia (three of five, $60 \%$ ) to those without dysphagia (six of nine, $67 \%$ ).

The amplitude and velocity of successful secondary peristalsis induced by the air boluses in the normal subjects was similar to that in the reflux patients (Table). For the water boluses, the amplitude of secondary peristalsis induced was similar in the two groups while secondary peristaltic velocity was slower in the reflux patients.

Figure 4 summarises the patterns of the motor responses to air and water injection. In the normal subjects, $52 \%$ of the air injections triggered a peristaltic response and $21 \%$ resulted in failed peristaltic sequences. Of the remainder, $4 \%$ resulted in synchronous responses and $23 \%$ in no response. The reflux patients showed a distinctly different pattern; only $14 \%$ of air injections resulting in complete secondary peristalsis and $63 \%$ producing no response. The percentage of failed $(13 \%)$ and synchronous $(10 \%)$ responses were similar to those in the normal group. The difference between the two groups was maintained even when the patients with abnormal peristalsis were excluded from the analysis. The pattern of responses to the water bolus injections were similar to those seen for the air injections in the two groups.

\section{Balloon distension}

Balloon distension produced a manometric response that differed from the responses produced by the air and water bolus injections. Characteristically, during distension of the balloon, a high amplitude synchronous contraction was seen above the balloon while below the balloon there was motor quiescence. After deflation of the balloon the synchronous contraction above the balloon subsided and a peristaltic or synchronous wave was seen below the level of the balloon. Figure 5 shows the proportions of secondary peristaltic responses seen below the balloon after deflation. The frequency of secondary peristalsis after balloon distension in the patients with reflux disease $(20 \%)$ was similar to that in the control subjects $(0 \%)$, $(p=0.95)$ and, in the patients with reflux disease, was not influenced by the presence or absence of oesophagitis. The contraction amplitude and peristaltic velocity of the successful secondary peristaltic responses that occurred after balloon deflation were also similar in the normal subjects and the reflux patients (Table).

Figure 6 shows the patterns of balloon responses. There were no significant differences 
Figure 5: Percentage of secondary peristalsis with balloon distension. Each point represents the proportion of normal secondary peristaltic responses (out of five tests) for each subject. Subjects with normal primary peristalsis are represented by the filled circles and those with abnormal primary peristalsis with the open circles. The horizontal bars show median values. The response rates are similar in the two groups $(p=0.95)$.

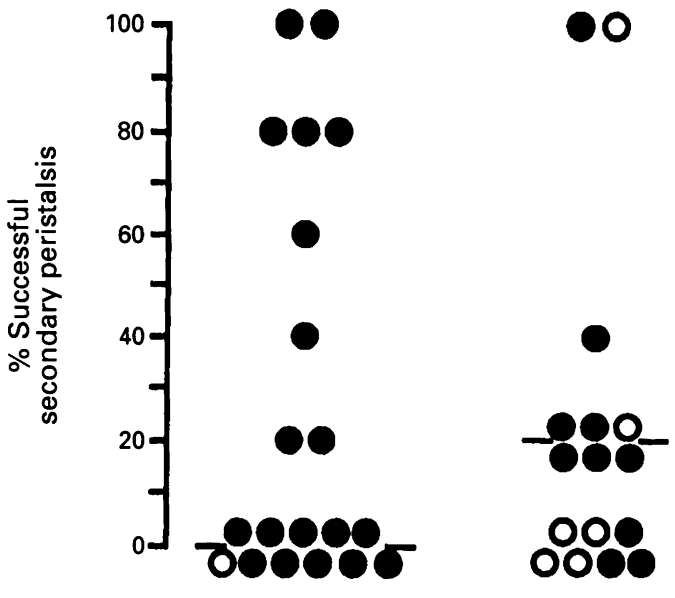

Normal

Reflux in the proportions of the motor responses either above or below the balloon between the two groups.

\section{Discussion}

The important finding from our study is that patients with reflux disease have considerably lower secondary peristaltic response rates than have aged matched controls with most patients failing to trigger any peristaltic response at all. This finding supports and extends earlier findings on spontaneous reflux episodes, which showed that secondary peristalsis occurred less frequently after reflux in patients with reflux oesophagitis compared with normal subjects. ${ }^{10}$ In this study it was also noted that the time from the onset of reflux to the first clearance motor event was prolonged in patients with reflux oesophagitis, a finding that could be explained, at least in part, by failure of secondary peristalsis. Although our findings are at variance with previous studies that found no difference in the frequency of secondary peristalsis between normal subjects and patients with reflux disease, ${ }^{12} 13$ it is possible that differences in methodology account for the discrepancy as the previous studies used slow infusions rather than rapid bolus injections used in this study.

The mechanisms underlying defective secondary peristalsis remain to be defined but inferences are possible from the pattern of the responses and from previous findings. As secondary peristalsis is a reflex response to oesophageal distension, the defect may lie in the oesophageal motor nerves or muscles, oesophageal sensation, the central integrative mechanisms or a combination of these. Most patients with abnormal primary peristalsis also had abnormal secondary peristalsis and in these patients we postulate that the defect lies in the efferent limb of the motor pathway. Most patients with abnormal secondary peristalsis, however, had normal primary peristalsis. Because secondary peristalsis seems to share a common motor pathway with primary peristal$\operatorname{sis}^{6}$ this side of the reflex would seem to be intact, implying that the defect in secondary peristalsis is due either to an abnormality of oesophageal sensation or in the integration of sensory information with the motor component of the reflex. This hypothesis is supported by the findings of Williams et al who noted that the distension threshold required to trigger a motor response was higher in patients with oesophagitis than in healthy controls. ${ }^{11}$ Others, however, have found no difference in the threshold volume required to trigger oesophageal motor responses using slow $(1 \mathrm{ml} / \mathrm{s})$ infusions. ${ }^{12} 13$ Differences in the methods of these other studies, however, make direct comparisons with our results difficult and further studies are needed to define more accurately the mechanisms responsible for defective secondary peristalsis in patients with reflux disease.

The importance of defective triggering of secondary peristalsis to the pathogenesis of reflux disease remains to be determined. Secondary peristalsis can effectively clear almost all of an injected acid bolus from the oesophagus leaving a negligible residual volume. ${ }^{8}$ The occurrence of secondary peristalsis after up to $57 \%$ of reflux episodes in normal subjects suggests a potential role in acid clearance after spontaneous reflux. ${ }^{10}$ The substantially lower occurrence rate of $17 \%$ in patients with reflux oesophagitis further suggests that defective secondary peristalsis might prolong acid clearance. It has been argued that because secondary peristalsis does not restore oesophageal $\mathrm{pH}$ to above $\mathrm{pH} 4$ it is not of physiological importance. ${ }^{21}$ As it acts in the initial clearing of the bulk of the refluxate volume from the oesophagus, however, changes in oesophageal $\mathrm{pH}$ would be unlikely until neutralisation of the residual acid by bicarbonate rich saliva delivered by primary peristalsis. ${ }^{8}$ Thus secondary peristalsis would not by itself be expected to restore oesophageal $\mathrm{pH}$, but to complement and accelerate the effects of the primary peristalsis that follows. During the day when patients are awake, any effect of defective secondary peristalsis on acid clearance will be minimised by frequent primary peristalsis. Secondary peristalsis is likely to be more important, however, during sleep when the rate of primary peristalsis is substantially reduced. ${ }^{22}$ This notion is supported by our recent finding in normal subjects during concurrent ambulatory manometry and $\mathrm{pH}$ monitoring that while primary peristalsis was the most common initial oesophageal clearance event overall, secondary peristalsis was the important initial motor event when the subjects were supine or asleep, or both. ${ }^{23}$

Non-obstructive dysphagia is a common symptom in patients with gastro-oesophageal reflux disease and correlates with the severity of primary peristaltic abnormalities. ${ }^{24}$ We hypothesised that a similar correlation would also exist for patients with dysphagia and abnormal secondary peristalsis. Instead, in patients with normal primary peristalsis, the prevalence of defective secondary peristalsis was similar in those with dysphagia $(60 \%)$ to that in patients without dysphagia (67\%) suggesting that defective secondary peristalsis does not contribute to non-obstructive dysphagia in patients with gastro-oesophageal reflux disease.

The nature of the distending stimulus determined the manometric pattern of the 


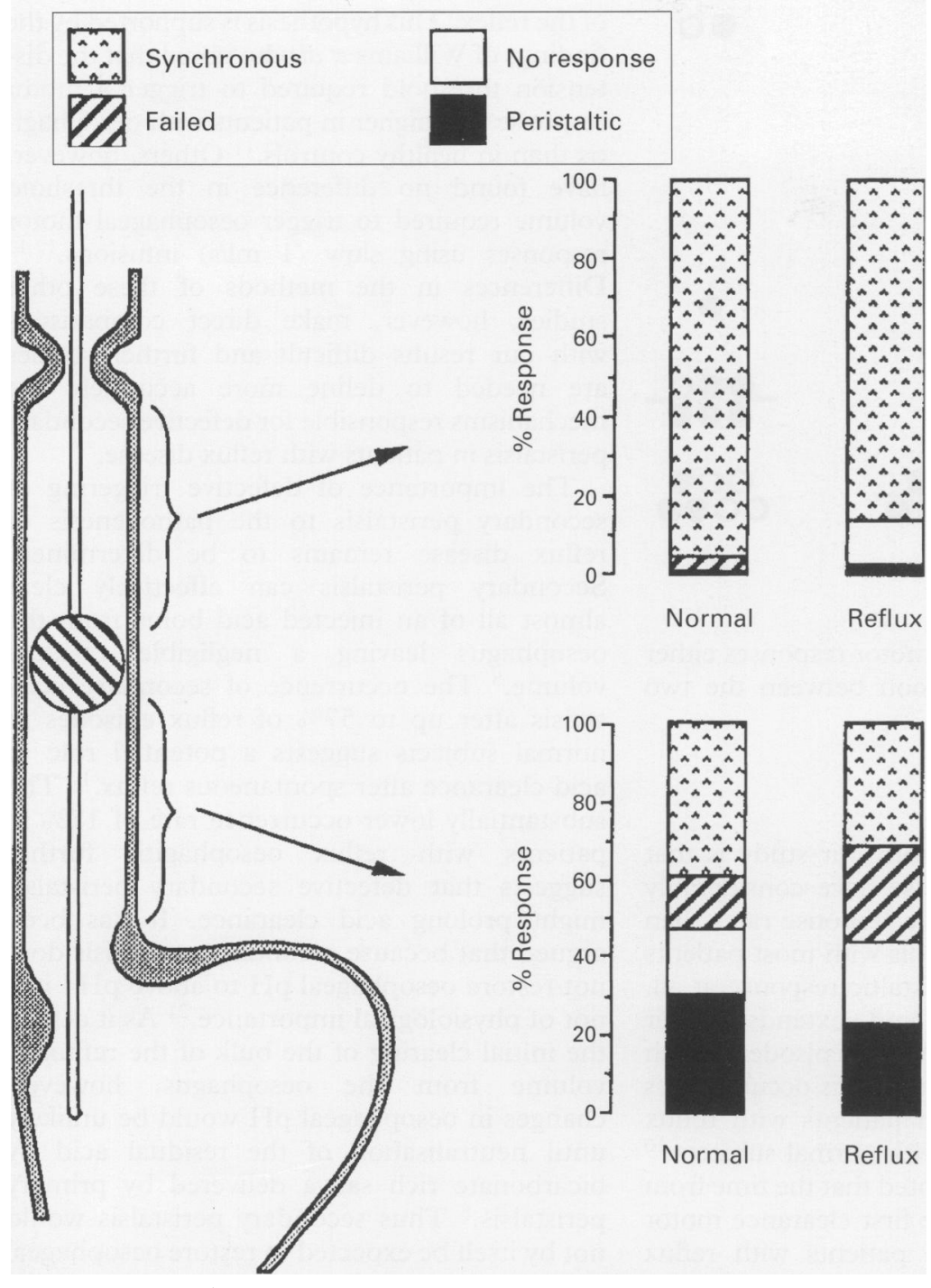

Figure 6: Patterns of manometric response to balloon distension. The proportion of various patterns of manometric response are derived from pooled data of the individual responses. Responses have been divided into those occurring above and below the balloon with the responses above the balloon occurred during inflation and the responses below the balloon occurred after deflation. The pattern of the responses was similar in the two groups.

secondary peristaltic responses we recorded. The air and water boluses were distributed rapidly along the length of the oesophagus as shown by the common cavity seen in the oesophageal body after injection. This pattern of distension triggers an integrated response that sweeps the length of the oesophagus. Distension with air or water produces a pattern of distension analogous to the oesophageal distension induced by reflux; the $10 \mathrm{ml}$ bolus producing a common cavity pressure rise that is similar to that seen after reflux events. As in normal subjects, ${ }^{5}$ air and water boluses were also more effective stimuli for inducing secondary peristalsis in normal subjects and discriminated normal subjects from patients with reflux disease more clearly than did balloon distension. Fixed balloon distension, on the other hand, produces a manometric response more analogous to acute oesophageal obstruction, ${ }^{7}$ and the propagated response associated with balloon deflation occurs only below the site of distension. It is also a suboptimal stimulus as evidenced by the lower response rate compared with those to air and water in the normal subjects, and its failure to discriminate between normal subjects and patients with reflux disease.

In summary, we have shown a substantial defect of triggering of secondary peristalsis in patients with reflux disease. The significance of this abnormality to the pathogenesis of reflux disease, in particular oesophageal acid clearance, requires further study.

This project was supported by a project grant from the National Health and Medical Research Council. Dr Schoeman is supported by a National Health and Medical Research Council Postgraduate Scholarship and a Royal Adelaide Hospital Dawes Scholarship. The valuable support and assistance of Professor John Dent in the development of the recording apparatus and for reviewing the manuscript is gratefully acknowledged. The authors also thank $\mathrm{Mr}$ Marcus Tippett for his technical suppor and assistance. This study was presented at the American Gastroenterology Association scientific meeting in New Orleans, May 1991 and published in abstract form in Gastroenterology, May 1991.

1 Creamer B, Schlegel J. Motor responses of the esophagus to distension. J Appl Physiol 1957; 10: 498-504.

2 Dornhurst AC, Harrison K, Pierce JW. Observations on the normal oesophagus and cardia. Lancet 1954; 695-8.

3 Fleschler B, Hendrix TR, Kramer P, Ingelfinger FJ. The characteristics and similarity of primary and secondary peristalsis in the esophagus. F Clin Invest 1959; 38: $110-6$.

4 Paterson WG, Rattan S, Goyal RK. Esophageal responses to transient and sustained esophageal distension. $A m \mathcal{J}$ Physiol 1988; 255: G587-95.

5 Schoeman MN, Tippett M, Ireland A, Dent J, Holloway RH Stimulation and characteristics of secondary oesophageal peristalsis in normal subjects. Gut $1994 ; 35: 152-8$.

6 Siegel CI, Hendrix TR. Evidence for the central mediation of secondary peristalsis in the esophagus. Bull fohn Hopkins Hosp 1961; 108: 297-307.

7 Winship DH, Zboralske FF. The esophageal propulsive force: esophageal response to acute obstruction. $\mathcal{f}$ Clin Invest 1967; 46: 1391-401.

8 Helm JF, Dodds WJ, Pelc LR, Palmer DW, Hogan WJ, Teeter BC. Effect of esophageal emptying and saliva on clearance of acid from the esophagus. N Engl F Med 1984; 310: $284-8$

9 Dent J, Dodds WJ, Friedman RH, Sekiguchi T, Hogan WJ, Arndorfer RC, et al. Mechanism of gastroesophageal reflux in recumbent asymptomatic human subjects. $f \mathrm{Clin}$ Invest 1980; 65: 256-67.

10 Dodds WJ, Kahrilas PJ, Dent J, Hogan WJ, Kern MK, Arndorfer RC. Analysis of spontaneous gastroesophagea reflux and esophageal acid clearance in patients with reflux esophagitis. Fournal of Gastrointestinal Motility 1990; 2: $79-89$.

11 Williams D, Thompson DG, Marples M, Heggie L O'Hanrahan T, Mani V, et al. Identification of an abnormal esophageal clearance response to intraluminal distension in patients with esophagitis. Gastroenterology 1992; sion in patients

12 Corazziari E, Pozzessere C, Dani S, Anzini F, Torsoli A Intraluminal $\mathrm{pH}$ and esophageal motility. Gastroenterology 1978; 75: 275-7.

13 Corazziari E, Materia E, Pozzessere C, Anzini F, Torsoli A Intraluminal $\mathrm{pH}$ and oesophageal motility in patients with gastro-oesophageal reflux. Digestion 1986; 35: 151-7.

14 Dent J. A new technique for continuous sphincter pressure measurement. Gastroenterology 1976; 71: 263-71.

15 Arndorfer RC, Stef JJ, Dodds WJ, Linehan JH, Hogan WJ Improved infusion system for intraluminal esophageal manometry. Gastroenterology 1977; 73: 23-7.

16 Kahrilas PJ, Dodds WJ, Hogan WJ. Effect of peristaltic dysfunction on esophageal volume clearance. Gastroenterology 1988; 94: 73-80.

17 Hewson E, Ott D, Dalton C, Chen Y, Wu W, Richter J. Manometry and radiology. Complementary studies in the assessment of esophageal motility disorders. Gastroenterology 1990; 98: 626-32.

18 Richter JE, Wu WC, Johns DN, Blackwell JN, Nelson JL Castell JA, et al. Esophageal manometry in 95 healthy adult volunteers. Dig Dis Sci 1987; 32: 583-92.

19 Bishop YMM, Fienberg SE, Holland PW. Discrete multivariate analysis: theory and practice. Cambridge, MA: The MIT Press, 1975.

20 Brunning JL, Kintz BL. Computational handbook of statistics. 3rd ed. Glenview, Illinois: Harper Collins, 1987.

21 Bremner R, Costantini M, DeMeester T, Shibberu H, Halls J, Crookes P. Secondary peristalsis is rare and is not
, S Important in clearing the esophagus of refluxed gastric important in clearing the esophagus of
acid. Gastroenterology 1992;102: A430.

22 Orr WC, Robinson MG, Johnson LF. Acid clearance during sleep in the pathogenesis of reflux esophagitis. Dig Dis Sci 1981; 26: 423-7.

23 Schoeman MN, Tippett MD, Akkermans LMA, Dent J, Holloway RH. Mechanisms of gastroesophageal reflux in ambulant healthy human subjects. Gastroenterology 1995 (in press)

24 Jacob P, Kahrilas P, Vanagunas A. Peristaltic dysfunction associated with nonobstructive dysphagia in reflux disease. Dig Dis Sci 1990; 35: 939-42. 